Engs, Ruth C. and Marlene Aldo-Benson, "The Association of Alcohol Consumption with SelfReported Illness.” Psychological Reports, 76:727-736, 1995.

This is the draft of the article and is found in IUScholarworks: http://hdl.handle.net/2022/26441

\title{
THE ASSOCIATION OF ALCOHOL CONSUMPTION WITH SELF-REPORTED ILLNESS IN UNIVERSITY STUDENTS *
}

\author{
Ruth C. Engs, Department of Applied Health Science Indiana University, Bloomington \\ Marlene Aldo-Benson Indiana University and Methodist Hospital of Indiana, Indianapolis \\ This study was funded by Indiana University. Copies of the Student Health and Lifestyle Questionnaire \\ used in this study are available on IUScholarworks: http://hdl.handle.net/2022/17338
}

\section{SUMMARY}

Many reports over the years have indicated an association between alcohol consumption and infectious illness among chronic heavy drinkers; however, many patients in these studies have been chronically ill. Thus the question of whether alcohol can appreciably influence immunity in humans and affect the incidence of infectious diseases remains largely unanswered. For this study over 1,100 undergraduate students from a general education course at large midwestern university were surveyed. Students were asked about their drinking habits and acute health problems. Analyses showed no increase in acute health problems or upper respiratory infections in students drinking between one and 21 drinks per week. However, students drinking 28 or more alcoholic drinks per week had significantly more health problems in the aggregate and those drinking more than 22 drinks per week had more upper respiratory infections compared to the other students including non drinkers. It was concluded that excessive alcohol intake increased the risk of respiratory infections and acute illnesses in this sample of students, but more moderate alcohol consumption had little effect on the risk for these health problems.

\section{INTRODUCTION}

The literature suggests that alcohol consumption can increase health problems and infectious diseases. There is clinical evidence of increased incidence of infections among alcoholics (Roselle, 1992). For example, it is well known that chronic alcoholics have increased incidence of bacterial pneumonia (Nelson, Shellito, Mason \& Summer, 1992; Winterbauer, Bedon \& Ball, 1969). Chronic alcoholism is also associated with tuberculosis (Jacobson, 1992). One explanation proposed for this phenomenon is that alcohol suppresses the immune system (Majchrowica and Weight, 1986). Some studies of humans and animals have shown that alcohol can suppress the immune system (Aldo-Benson, 1989; Aldo-Benson, Kluve-Beckerman, Hardwick, Lockwood, 1992). On the other hand, others have indicated no supression (Grossman, Mendenhall \& Roselle, 1988) and one has shown that up to four drinks per day decreases the risk for developing "colds" among healthy human volunteers (Cohen, Tyrrell, Russell, Jarvis, \& Smith 1993). A problem with this line of research is that many investigations of alcohol on the immune function have used chronic alcoholics as subjects (Watson, Jackson, Hartmann, 
Sampliner, Mobley, \& Eskelson, 1985). Thus, the results with this population may be confounded with the effects of heavy alcohol ingestion on the liver or other organ systems.

In general, college students are healthy, but they do develop infectious diseases and other acute health problems. Urinary tract, sexually transmitted, upper respiratory, and streptococcal infections are commonly reported (Faigel, 1990; Christmas \& Berkowitz, 1989; Turner, Hayden, Kiselica, Fishburne, Lohr, Murren, \& Dudley, 1989). Other problems such as injuries and emotional problems also occur (Meilman, Yanofsky, Gaylor, \& Turco, 1989). At the large midwestern university where these data were collected, approximately 45,000 visits to the student health center for a campus of over 30,000 students occurred during the 1991-1992 academic year (Reese, 1993). However, the center does not break visits into different categories such as infectious diseases and other illnesses. About $6 \%$ of university students have chronic illness such as cystic fibrosis or diabetes mellitus (Patrick, 1992).

The drinking habits of college students in the United States have been well described and characterized over the past 20 years. A review of many studies in the past decade can be found in Engs \& Hanson's (1994b) latest article. These studies suggest that about $80 \%$ of all college students consume alcohol at least once a year with men consuming more than women. About $20 \%$ of students are heavy drinkers [sometimes called "binge drinking"]. Acute conditions related to alcohol intoxication such as hangover, vomiting or injuries are common among this group (Hanson and Engs, 1992; Meilman, et al, 1989). Because college students tend to be relatively healthy, they were considered ideal for a study examining the risk of infectious illness, as a reflection of immune function, and acute health problems associated with alcohol intake.

The purpose of this study was to examine self-reported acute and infectious illness in relation to the mean amount of alcohol consumed per week.

\section{METHODS}

\section{Subjects}

During the 1991-1992 academic year, almost 1,200 undergraduate students were enrolled in the general education survey course "personal health" at a large Midwestern university. Students attending this course were from all majors and class years. The Lifestyle Questionnaire, described below, was administered to these students during the first week of class. The questionnaire was completed by 1,150 students. Of these responses, 35 cases were rejected due to obviously faked responses, i.e., consuming 99 beers a day, or incomplete data, leaving a total sample of 1,115 students. There were 484 men and 631 women, a proportion similar to that of men and women attending institutions of higher learning (Snyder 1991). All subjects were between 17 and 35 years of age (mean age $19.6 \pm 3.2$ ) and were assumed to be basically healthy.

\section{Lifestyle Questionnaire Development}

A Lifestyle Questionnaire, to test for self-reported illness and lifestyle behaviors such as alcohol consumption and smoking, was developed based upon items in two survey instruments used previously by the first author (Engs and Hanson, 1994a; Engs, Hanson, Gliksman \& Smythe, 
1990). Items selected for incorporation into the new questionnaire included common student health problems and those that measure drinking patterns. Since the authors wished to test the hypothesis that drinking is associated with infectious diseases, various symptoms of upper respiratory infections including cough, sore throat, cold or flu, bronchitis were included. In addition health problems related to the immediate sequelae to episodes of heavy drinking such as stomach upset, nausea and diarrhea were used along with injuries and accidents. Other health problems common to students such as sexually transmitted diseases, urinary tract and vaginal infections, and skin and emotional problems were also asked.

\section{Instrument reliability and calculating Health Problem Scores}

Because some of the health items were reworded and because a total score for an aggregate of health problems was desired for this study, new reliability and validity procedures were carried out. Face validity of the instrument was assessed by asking 90 students to clarify all illness related items. The test-retest reliability was accomplished with 206 students. The instrument was administered on two occasions with an interval of two weeks. The test-retest reliability coefficient was .89. Seven items with reliability coefficients less than .20 were eliminated from the questionnaire.

Construct validity, to test for possible underlying themes for different health categories, was tested by use of the factor analysis technique which gave six factors. Since there were low correlations among the six factors, a regression analysis was carried out to derive a formula for calculating a Total Health Problem Score. Three factors accounted for $85 \%$ of the variance, namely Gastrointestinal, Upper Respiratory Infections, and General Malaise. Symptoms clustered in the Upper Respiratory factor included sore-throat, a cold or the "flu", cough, bronchitis or laryngitis, and ear infection; the Gastrointestinal factor included stomach upset, nausea or vomiting, and diarrhea; and the General malaise factor included headache and lack of energy. Cronbach's Alpha measurement of homogeneity for the items indicated a reliability coefficient of .70 for the instrument.

To calculate an illness category score, students were asked to indicate how many times they had experienced a given health problems during the previous month. The number of each responses was tallied within the appropriate illness category. For example, if a student indicated $\mathrm{h} / \mathrm{she}$ had suffered once from a cold, twice from a cough and none for a sore throat, a score of 3 (three) would be calculated for the Upper Respiratory Infections category.

The three illness categories were used to calculate the Total Health Problem Score using the following regression formula resulting from the analysis: Total Illness Score $=1.3+1.1$ (Upper Respiratory Infections $)+1.6$ (Gastrointestinal $)+1.0$ (General Malaise $)$. It needs to be kept in mind that this score is not the number of illnesses the student experienced, but rather a weighted total score determined by regression analysis of the factors and represents an aggregate the health problems.

\section{Drinking Behaviors}


To estimate drinking behaviors, the six Quantity-Frequency items from the Student Alcohol Questionnaire were used (Engs, 1977; Engs and Hanson, 1994a). Students were requested to indicate the average frequency of drinking beer, wine and spirits and the average number of these drinks consumed on any one occasion during the past month.

Several methods for calculating the amount of alcohol consumed are in common use. They include calculating the mean grams or ounces of absolute alcohol or mean drinks or units per week or per day. In self report studies, determining grams or ounces is often an imprecise calculation as it is based upon recall. Moreover, people tend to underestimate the amount they have consumed (Thomas, Goddard, Hickman \& Hunter 1993).

Therefore, in recent years it has become more common to calculate the mean number of drinks, or units, per week or day of all alcoholic beverages consumed (Lemmon, Tan \& Knibbe, 1988; Engs, Hanson, Gliksman \& Smythe, 1990; Thomas, Goddard, Hickman \& Hunter 1993; Engs 1990; Engs \& Hanson, 1994b; Gaziano, Buring, Breslow, Goldharber, Rosner, VanDenburgh, Willett \& Hennekens, 1993). Calculations for this method are based upon the "rule of thumb" that an average can or glass of tavern beer( 12 ounces) is roughly equivalent to an average size glass of wine (5 ounces) or shot of spirits (one and half ounce) in terms of grams (approximately 13) of absolute alcohol(Consumer and Food Economics Institute, 1990).

For this study, the mean number of drinks consumed per week were assessed as follows. Loading values for the frequency of consuming each beverage were assigned the following numbers. "Every day" = 7, "Two or three times a week" $=3.5$, "Once a week" = 1, "At least once a month but less than once a week" $=.25$, and "not at all" $=0$. This loading value was multiplied by the average number of drinks consumed at any one sitting for each of the three beverages. The products of these three results were summed giving the mean number of drinks consumed per week for all alcoholic beverages. The mean number of drinks per week were categorized in Quantity-Frequency consumption levels as follows: Under 1 = "abstainer," 1-7 = "light," 8-14 = moderate," 15-21 = "moderate-heavy," 22-28 = "heavy" and 29 plus = "at risk drinker."

Because tobacco has also been shown to be associated with illness, its use was also assessed to rule out results which might be associated with smoking only. To provide a Quantity-Frequency score for cigarettes, the number of cigarettes smoked per day was multiplied by the loading value used for the alcohol frequency.

\section{Study Design and Statistical Analysis}

A Cross sectional design was used. For analysis a univariant one-way analysis of variance was used to test differences between Total Health Problem Scores, Upper Respiratory Infections and Gastrointestinal problems and each drinking category. For resulting significant differences, the post hoc Scheffe test was used to identify pairs of means which differed significantly. Because men and women differ in their drinking patterns (Engs and Hanson 1990), they were initially analyzed separately.

The data were analyzed again with cigarette consumption to control for any differences due to smoking. For this analysis, a 2 (smoking status) X 6 (drinking levels) design was used. A one- 
way analysis of variance calculation in the MANOVA Statistical Package for Social Science (SPSS)(Norusis, 1990) was utilized for each of the categories.

A basic assumption in survey research is that college students are willing to answer honestly brief anonymous self-report questionnaires. In general, research has indicated that of the many published studies using the drinking subscale of this instrument, that only a small percent of the sample $(2 \%)$ have had to be rejected because of obviously faked responses or incomplete data (Engs, 1990). Students are likely to under report data; however, we can not be certain that the convenience sample used for this study is generalizable to all individuals in this age group.

\section{RESULTS}

The mean amount of alcohol consumed for the total group was 10.4 drinks per week. As has been found in most studies, men consumed significantly more drinks per week than women (15.7 and 5.7 respectively). This consumption is similar to a national study of college students using the same questionnaire where the total amount consumed was 11.4 drinks per week for the total sample, 16.3 drinks per week for men and 8.2 for women (Engs 1990).

The mean score for the Total Health Problem Score for the total sample was $22.4 \pm 22.3$. The mean scores for Upper respiratory, Gastrointestinal and General malaise were 5.8 $\pm 10.0,4.1 \pm 8$, and $7.9 \pm 8.6$ respectively. There were no significant differences between men and women for the Total Health Score (22.2 and 22.1), Upper Respiratory (4.3 and 3.9) or the Gastro-intestinal (6.5 and 5.3) scores respectively. Because there was no significant difference in these scores between men and women and because the purpose of the study was to examine the relationship of infectious disease and acute illness to alcohol consumption, the combined sample was used for the rest of the analysis.

The Total Health Problem Scores for the different drinking groups for all 1,115 subjects are shown in Figure 1. Results of the uni-variant one-way ANOVA shows a significant difference ( $\mathrm{p}$ $<.001)$ between the drinking levels and the Total Health Problem Score $(\mathrm{F}=5.2, \mathrm{df}=5, \mathrm{df}=1109$, Sum of Squares=12823.1, Mean Squares=2564.6). The post-hoc Scheffe test revealed the significant pairs occurred between individuals drinking over 28 drinks per week and those consuming seven or less per week. 


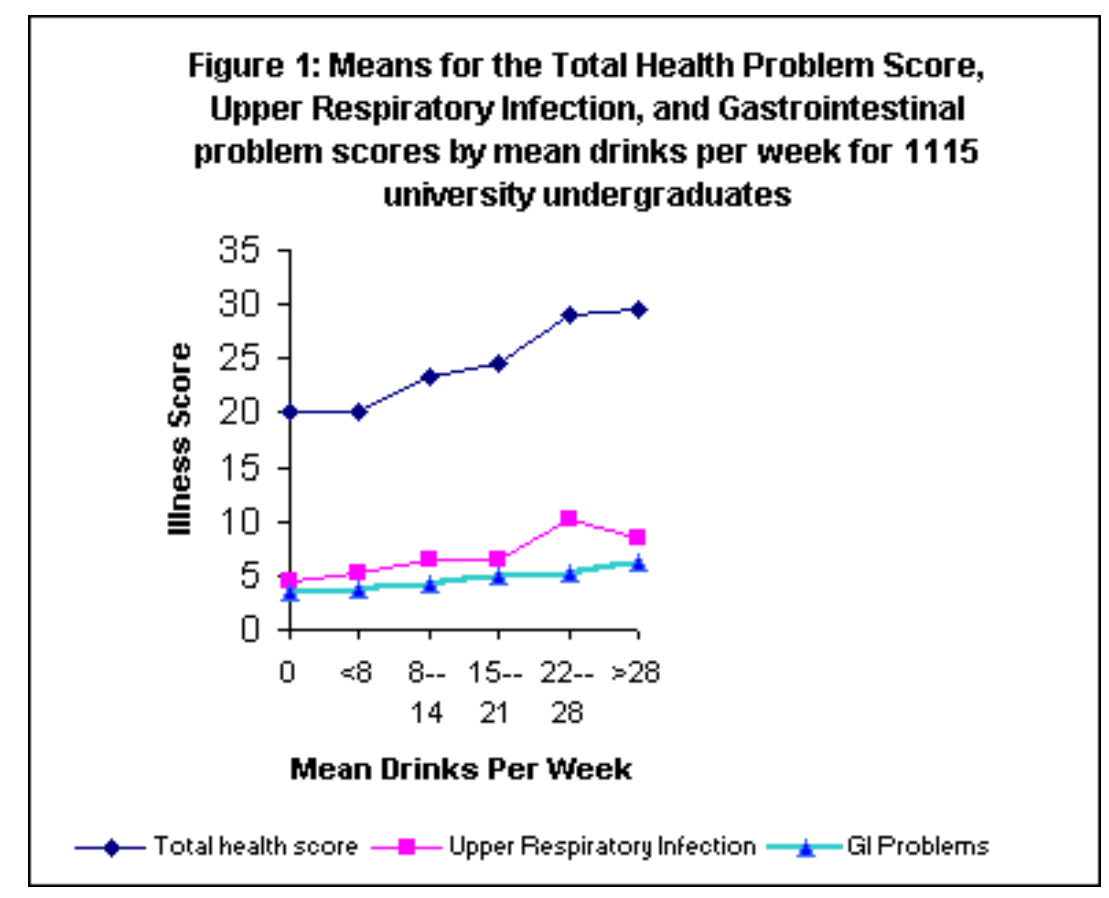

When the Upper Respiratory score was analyzed, the ANOVA revealed a significant difference $(\mathrm{p}<.001, \mathrm{~F}=5.2, \mathrm{df}=5, \mathrm{df}=1109$, Sum of Squares=2555.5, vMean Squares=511.1) between the different drinking levels(see Figure 1). The post-hoc test revealed that the Upper Respiratory score was significantly greater among the "heavy" drinkers (22 to 27 drinks per week), compared to those who consumed under seven drinks per week. When Gastrointestinal problems alone were examined, there was a significant $(\mathrm{p}<.05)$ difference between the drinking groups $(\mathrm{F}=2.5, \mathrm{df}=5, \mathrm{df}=1109$, Sum of Squares=801.8, Mean Squares=160.4). However, the posthoc analysis showed no differences between any two pairs of mean scores. There was no significant difference between or within any variable for the Malaise Score, thus, these data are not reported in Figure 1.

Table 1: 2 (Smoking) x 6 (Drinking Level) Analysis of Variance For The Total Health Problem Score Among 1115 University Students

\begin{tabular}{|c|c|c|c|c|}
\hline SOURCE & $d f$ & $S S$ & Mean Sq. & $F$ \\
\hline Within cells & 1103 & 536993.2 & 486.8 & \\
\hline Six drinking levels & 5 & 7570.0 & 1514.0 & $3.1^{*}$ \\
\hline Smoking status & 1 & 3637.5 & 3637.5 & $7.5 *$ \\
\hline Drk lev. X Smk. & 5 & 2716.4 & 543.3 & 1.2 \\
\hline
\end{tabular}

Because smoking has a significant effect on the health of individuals, further analysis was attempted to see whether the results could be due to cigarette use and not alcohol. The results of the 2 (smoking) X 6 (drinking levels) analysis of the Total Health Problem Score showed a 
significant $(\mathrm{p}<.05)$ main effect between the six levels of alcohol consumption independent of smoking. There was no significant interaction between drinking levels and smoking status for Total Health Problems (Table 1). Results for Upper Respiratory problems, also, revealed a significant $(\mathrm{p}<.01)$ main effect between the six levels of alcohol consumption independent of smoking. Likewise there was no significant interaction between drinking and smoking for the Upper Respiratory score (Table 2). No significant difference for the gastrointestinal problems with either smoking or alcohol consumption were found. Power analysis showed statistical adequate sample size for the drinking levels and smoking groups for all the significant categories (ranging from .67 to .88).

Since there was an association with drinking and smoking levels for the Total Health Problem and for Upper Respiratory Infection scores, a stepwise multiple regression analysis for each of these two variables was calculated. The results revealed that $4 \%$ of the explained variance was due to alcohol $(\mathrm{F}=34.8, \mathrm{df}=1, \mathrm{df}=965$, Sum of Squares 16704.3, $\mathrm{p}<.001, \mathrm{r} 2=.04)$. There was no significant effect

Table 2: 2 (Smoking) x 6 (Drinking Level) Analysis of Variance For Upper Respiratory Infections Among 1115 University Students

\begin{tabular}{|c|c|c|c|c|}
\hline SOURCE & $d f$ & $S S$ & Mean Sq. & $F$ \\
\hline Within cells & 1103 & 108127.8 & 98.0 & \\
\hline Six drinking levels & 5 & 1479.4 & 295.9 & $3.0^{*}$ \\
\hline Smoking status & 1 & 533.2 & 533.2 & $5.4^{*}$ \\
\hline Drk lev. X Smk. & 5 & 575.6 & 115.1 & 1.2 \\
\hline
\end{tabular}

from smoking. For Upper Respiratory Infections, the regression analysis revealed that $1 \%$ of the explained variance was due to alcohol consumption and that there was no significant effect from $\operatorname{smoking}(\mathrm{F}=8.8, \mathrm{df}=1, \mathrm{df}=965$, Sum of Squares=15.0, $\mathrm{p}<.01, \mathrm{r} 2=.01)$.

\section{DISCUSSION}

The data show that alcohol consumption of over 28 drinks per week was associated with a higher total health problem score which included gastrointestinal, upper respiratory and general malaise problems. General malaise problem, such as headaches, along with gastrointestinal symptoms, could be the sequelae of acute alcohol intoxication. A primary purpose of this study was to determine the effect of alcohol consumption upon infectious illness as an indirect measure of general immune function. The data show that increased risk of acute upper respiratory infections occurred among those students consuming over 22 drinks a per week. These associations are not due to the fact that heavy drinkers also smoke more, because the relationship occurs even in nonsmokers; drinking was significant while controlling for a smoking effect. 
The regression analysis suggests that upper respiratory infections were only weakly predicted by heavier drinking. Smoking was not predictive of upper respiratory infections. Moreover, the positive association of alcohol consumption and upper respiratory infections hints at immune function depression among these heavier drinkers. Of course, other factors and behaviors associated with heavy drinking among these university students could have also depressed immune function and contributed to the results such as late night parties leading to lack of sleep, erratic eating patterns leading to poor nutrition, contact with contagious people in crowded taverns, and stress. It is recommended that research including these variables and differing amounts of alcohol ingestion in relationship to immune function be carried out to clarify this issue.

Of equal interest in this study is the finding that up to a mean of 21 drinks per week was not associated with increased incidence of Upper Respiratory infections. This suggests that "moderate" (7-14 drinks per week) to "moderate-heavy" (15-21 drinks per week) alcohol consumption, per se, did not add to acute health risks among these students. This is in agreement with other research which suggest that alcohol consumption from 1 to 3 or even 4 drinks per day, may have few harmful, and even a beneficial effects, on health (Bofetta and Garfinkel 1990; Rimm, Giovanucci, Willett, Colditz, Ascherio, Rosner \& Stampfer, 1993; Garg, Wagner \& Madans 1993; Cohen, et al, 1993; Gaziano, et al, 1993).

It was concluded that consuming over 22 drinks a week is associated with increased upper respiratory infections and over 28 drinks per week associated with acute illness in the aggregate among this sample of university students.

\section{REFERENCES}

Aldo-Benson, M.A. Mechanism of alcohol induced suppression of B cell response. Alcoholism: Clinical and Experimental Research, 1989,13,469-472.

Aldo-Benson, M.A., Kluve-Beckerman, B., Hardwick, J., \& Lockwood, M. Ethanol inhibits production of mRNA for kappa light chain in stimulated B lymphocytes. Journal Laboratory Clinical Medicine, 1992,119,80-82.

Bofetta, P. and Garfinkel, L. Alcohol drinking and mortality among men enrolled in an American Cancer Society prospective study. Epidemiology, 1990,1,342-348.

Christmas, W.A. \& Berkowitz, S.D. Sexual behavior and the structure of STDs on a college campus. Journal American College Health, 1989,38,40.

Cohen, S., Tyrrell, D.A., Russell, M.A., Jarvis, M.J., \& Smith, A.P. Smoking, alcohol consumption, and susceptibility to the common cold. American Journal of Public Health, 1993,83,1277-1283.

Consumer and Food Economics Institute. Composition of foods, Handbook 8 Series. Washington, DC: US Department of Agriculture, 1990 Engs, R.C. Drinking patterns and drinking problems of college students. Journal Studies of Alcohol, 1977,38,2144-2156. 
Engs, R.C. Family background of alcohol abuse and its relationship to alcohol consumption among college students: An unexpected finding. Journal Studies of Alcohol, 1990,51,542-547.

Engs, R.C. \& Hanson, D.J. Gender differences in drinking patterns and problems among college students: A review of the literature. Journal Alcohol and Drug Education., 1990,35,36-47.

Engs, R.C.. and Hanson, D.J. The Student Alcohol Questionnaire: An updated reliability of drinking patterns, problems knowledge and attitude subscales. Psychological Reports, 1994a,74,12-14.

Engs, R.C. and Hanson, D.J. Boozing and brawling on the campus: A national study of violent problems associated with drinking over the past decade. Journal of Criminal Justice, 1994b,22,171-180.

Engs, R.C., Hanson, D.J, Gliksman, L. \& Smythe, C. Influence of religion and culture on drinking behaviors:A test of hypotheses between Canada and the U.S.A. British Journal of Addictions, 1990,85,1474-1482. Faigel, H.C. The relationship between urinary tract infections and the collegiate academic calendar. Journal American College Health, 1990,39,77-81.

Garg, R., Wagener, D.K., \& Madans, J.H. Alcohol consumption and risk of ischemic heart disease in women. Archive of Internal Medicine, 1993,153,1211-1216.

Gaziano, J.M., Buring, J.E., Breslow, J.L., Goldharber, S.Z,. Rosner, R., VanDenburgh, M., Willett, W. \& Hennekens, C.H. New England Journal of Medicine, 1993,329,1829-34.

Grossman, C., Mendenhall, C.L. \& Roselle, G.A. Alcohol and immune regulation in in vivo effects of ethanol on concanovation: A sensitive thymic lymphocyte function.

International Journal Immunopharmacology, 1988,10,187-195.

Hanson, D.J. \& Engs, R.C. College students' drinking problems: A national study, 19821991. Psychological Reports, 1992,71,39-42.

Lemmens, P., Tan, E.S., \& Knibbe, R. Comparison of indices of alcohol consumption:Issues of validity of self-reports, Paper presented at the Fourth Annual Alcohol Epidemiology Symposium Berkeley, California, June 5-11, 1988.

Majchrowica, E. \& Weight, F.F. Effect of ethanol administration on parameters of immunocompetency in rats. Journal of Leukocyte Biology, 1986,39,499-510.

Meilman, P.W., Yanofsky, N., Gaylor, M.S. \& Turco, J.H. Visits to the college health service for alcohol-related injuries. Journal College Health Association, 1989, 37,205-210.

Nelson, S., Shellito, J., Mason, C. \& Summer, W.R. Alcohol and bacterial pneumonia. Alcohol Health and Research World, 1992,16,73-80. 
Norusis, M. SPSS Advanced Statistics: Student Guide, SPSS INC.: Chicago, 1990.

Patrick, K. Health issues for college students. Annual Review Public Health, 1992,13,253-268.

Jacobson, J.M. Alcoholism and tuberculosis. Alcohol Health and Research World, 1992,16,3947.

Reese, A. Private Communication. Indiana University Student Health Center, 1993.

Rimm, E.B., Giovanucci, E.L., Willett, W.C., Colditz, G.A., Ascherio, A., Rosner B \& Stampfer, M.J. Prospective study of alcohol consumption and risk of coronary disease in men. Lancet, $1991,338,464-468$.

Roselle, G.A. Alcohol and the Immune System. Alcohol Health and Research World, 1992,16,16-19.

Snyder, T.D., Digest of Education Statistics, 1991, 1991, Department of Education: Washington, DC.

Thomas, M., Goddard, E., Hickman, M. \& Hunter, P. General Household Survey 1992, Office of Population Censuses and Surveys, HMSO: London, 1993.

Turner, J.C., Hayden, G., Kiselica, D., Fishburne, C.N.D., Lohr, J., Murren, D., Joyner, P. \& Dudley, S. A preliminary study of non- group A Beta hemolytic streptococci as a possible cause of endemic pharyngitis. Journal of American College Health, 1989,38,25.

Watson, R.R., Jackson, J.C., Hartmann B., Sampliner, R., Mobley, D. \& Eskelson, C. Cellular immune function, endorphins and alcohol consumption in males. Alcoholism, Clinical and Experimental Research 1985,9,248-254.

Winterbauer, R.H., Bedon, G.A., Ball, W.D. Recurrent pneumonia predisposing illness and clinical patterns in 158 patients. Annuals of Internal Medicine, 1969,70,689-700.

\section{ACKNOWLEDGMENT}

We would like to thank David Koceja, PhD, Indiana University, Bloomington, for statistical and John Samuel, Stat-Math, Indiana University for computer consultation. 